\title{
Rapid Resolution of Carbohydrate Isomers by Electrospray Ionization Ambient Pressure Ion Mobility Spectrometry-Time-of-Flight Mass Spectrometry (ESI-APIMS-TOFMS)
}

\author{
Prabha Dwivedi, ${ }^{\mathrm{a}, \mathrm{b}}$ Brad Bendiak, ${ }^{\mathrm{c}}$ Brian H. Clowers, ${ }^{\mathrm{a}, \mathrm{b}}$ \\ and Herbert H. Hill Jr. ${ }^{a, b}$ \\ ${ }^{a}$ Department of Chemistry, Washington State University, Pullman, Washington, USA \\ ${ }^{\mathrm{b}}$ Center for Multiphase Environmental Research, Washington State University, Pullman, Washington, USA \\ c Cell and Developmental Biology and Biomolecular Structure Program, University of Colorado Health \\ Sciences Center, Fitzsimons Campus, Aurora, Colorado, USA
}

Carbohydrates are an extremely complex group of isomeric molecules that have been difficult to analyze in the gas phase by mass spectrometry because (1) precursor ions and product ions to successive stages of $\mathrm{MS}^{\mathrm{n}}$ are frequently mixtures of isomers, and (2) detailed information about the anomeric configuration and location of specific stereochemical variants of monosaccharides within larger molecules has not been possible to obtain in a general way. Herein, it is demonstrated that gas-phase analyses by direct combination of electrospray ionization, ambient pressure ion mobility spectrometry, and time-of-flight mass spectrometry (ESIAPIMS-TOFMS) provides sufficient resolution to separate different anomeric methyl glycosides and to separate different stereoisomeric methyl glycosides having the same anomeric configuration. Reducing sugars were typically resolved into more than one peak, which might represent separation of cyclic species having different anomeric configurations and/or ring forms. The extent of separation, both with methyl glycosides and reducing sugars, was significantly affected by the nature of the drift gas and by the nature of an adducting metal ion or ion complex. The study demonstrated that ESI-APIMS-TOFMS is a rapid and effective analytical technique for the separation of isomeric methyl glycosides and simple sugars, and can be used to differentiate glycosides having different anomeric configurations. (J Am Soc Mass Spectrom 2007, 18, 1163-1175) (c) 2007 American Society for Mass Spectrometry

$\mathrm{O}$ ligosaccharides, either alone or as glycoconjugates are actively involved in numerous biological phenomena such as cell-cell recognition, embryonic development, and differentiation [1-5]. Understanding their functional roles requires a detailed knowledge of their structures. Mass spectrometry has long been an important tool for analysis of oligosaccharides [6-8] but two crucial issues remain a challenge for enabling its use in structural elucidation of unknowns.

First, the inability to rapidly and unambiguously discriminate isomeric monosaccharides is a major impediment in the structural characterization of glycans. There are $16 \mathrm{D}$ - and L-aldohexoses, for example, and 8 D- and L-ketoses. They can exist in two anomeric configurations and two ring forms within an oligosaccharide in nature, yielding a total of 96 configurations, all having an identical $\mathrm{m} / \mathrm{z}$. When mass spectrometry is applied as a rapid gas-phase analytical tool stereochem-

Address reprint requests to Professor H. H. Hill, Jr. Department of Chemistry, Washington State University, Pullman, WA 99164-4630, USA. E-mail: hhhill@wsu.edu ical variants often dissociate to yield essentially identical mass spectra. Mass spectrometric discrimination of such isomers is thus often aided by one or more pre-mass analysis separation steps and the rapid nature of the technique is compromised. For example, individual monosaccharides obtained as hydrolysis products of oligosaccharides are best analyzed as linear derivatives such as aldononitrile acetates, 1-deoxy-1hydrazino-alditol acetates, or partially methylated alditol acetates [9-11]. Since the fragmentation patterns of different stereoisomers of the derivatives are often similar, unambiguous identification of stereochemical variants is achieved through one or more pre-mass analysis chromatographic separation steps in tandem to the MS analysis, such as GC-MS. However, following hydrolysis, no information can be gleaned about the anomeric configuration of the sugar or about its location within the original oligosaccharide molecule. This requires that oligosaccharides be manipulated in a controlled disassembly through multiple isolation/dissociation steps in the gas phase, whereupon at some later dissociation step a monosaccharide product ion at any 
stage of $\mathrm{MS}^{\mathrm{n}}$ might be isolated to identify its stereochemistry. This, however, is entirely a different feat than an up-front chromatographic separation. While some modern mass spectrometers such as ion traps and Fourier transform ion cyclotron resonance (FTICR) instruments are ideally suited to multiple isolation/dissociation steps, one ultimately faces the inevitable question: "If selection of ions is based solely on $\mathrm{m} / \mathrm{z}$, how can two isomers that produce essentially identical dissociation patterns be discriminated, as occurs with anomeric $(\alpha$ and $\beta$ ) monosaccharide product ions?" One answer to this may be ion mobility spectrometry (IMS), which separates gas-phase ions based on their size to charge ratio $[12,13]$. When coupled to the back end of a mass spectrometer, IMS might be utilized to separate isolated monosaccharide product ions or potentially other small ions generated by disaccharide dissociation immediately preceding an IMS step. However, before this becomes feasible, another fundamental question must be addressed. "Can gas-phase separation based on size to charge ratio (IMS) be exploited to differentiate gas-phase monosaccharide anomers or even small anomeric glycosides such as methyl glycosides?" It is also worth noting that other product ions larger than monosaccharides may be generated during multiple isolation/dissociation steps and they may be isomeric in nature. This is particularly true of many branched oligosaccharides where relatively large isomeric product ions can arise from different branches.

A second nettlesome problem in oligosaccharide analysis is that many samples from unknown sources are mixtures of isomeric oligosaccharides [14-17]. While chromatographic separations (i.e., HPLC) have been utilized for some time to isolate oligosaccharides, isomeric molecules usually prove to be the most difficult to separate and require some sort of evaluation of isomeric heterogeneity for which NMR has been wellsuited in the past. However, well below NMR levels (currently about $500 \mathrm{pmol}$ is the minimum for 1D NMR spectra), how can one be certain that a chromatographic peak is ever one isomer? Failure to evaluate isomeric heterogeneity risks deduction of a single (assumed) structure from data derived from a mixture of molecules. Recently, this issue has been addressed $[18,19]$ using mixtures of isomeric permethylated oligosaccharides and $\mathrm{MS}^{\mathrm{n}}$. These investigators demonstrated that isomers having different linkages may be predictably identified in mixtures because at some stage during $\mathrm{MS}^{\mathrm{n}}$ disassembly, different dissociation patterns are anticipated from substructures. This will no doubt be a valuable approach, even with underivatized oligosaccharides [20, 21]. However, replacement of a single sugar in an oligosaccharide with its anomer or epimer (for example, an $\alpha$-Glc with a $\beta$-Glc, or a GlcNAc with a GalNAc), would in many cases render them impossible to evaluate as a mixture with their anomeric or epimeric counterparts using typical gas-phase dissociation methods. This remains a serious problem because they yield sets of substructures after every round of dissociation where subsequent fragmentation of any given isolated ion $\mathrm{m} / \mathrm{z}$ furnishes identical product ion $\mathrm{m} / \mathrm{z}$ values. There are many examples of such isomeric mixtures [14-17] and IMS coupled to mass spectrometers (in this case at the front end) [22-24] may provide a route for evaluation of their heterogeneity that is complementary to fragmentation. Again, this assumes that IMS of high enough resolution is available and is flexible enough to resolve many such isomers.

Since its inception in 1970 under the name plasma chromatography [25], IMS has evolved as a rapid gasphase separation technique. It surpasses the resolving power of liquid chromatography and is similar to that of gas chromatography. Being a gas-phase separation technique, the time required for an IMS experiment is in the millisecond (ms) time range, which markedly reduces analysis time and increases sample throughput. Only a few studies involving the application of IMS to carbohydrates have been reported [26-31]. None of these studies has demonstrated the separation of anomeric glycosides such as simple methyl glycosides or separation of isomers of reducing monosaccharides themselves potentially representing different anomers or ring forms of the ions. Some di- and trisaccharides have been resolved, both by high-field asymmetric waveform ion mobility spectrometry (FAIMS) using decanoic acid derivatives [26] or recently using ambient pressure IMS [31].

It is demonstrated here for the first time that highresolution IMS at ambient pressure can resolve anomeric methyl glycosides, and that the extent of separation varies with the nature of a complexing ion and the IMS drift gas. It is also reported that free reducing sugars as metal ion adducts can resolve into more than one peak. Additional peaks may represent different anomeric configurations or ring forms of the reducing sugars.

\section{Experimental}

\section{Instrument}

The instrument used in this study was an electrospray ionization ambient pressure ion mobility spectrometer coupled to an orthogonal time-of-flight mass spectrometer (ESI-APIMS-TOFMS). The details of APIMS and TOFMS along with the data acquisition system are reported in a previous publication [32].

The ion mobility spectrometer with basic stackedring design $[33,34]$ was used in this study and constructed at Washington State University. The APIMS tube consisted of alternating alumina spacers and stainless steel rings with high-temperature resistors connecting the stainless steel rings ( $500 \mathrm{k} \Omega$ resisters for the desolvation region, $1 \mathrm{M} \Omega$ resisters for the drift region). Ions were gated into the drift region of the IMS tube by a Bradbury-Nielsen type ion gate which also divided the IMS tube into a desolvation region and a drift region. The drift gas (nitrogen, unless otherwise noted) 
was introduced at a flow rate of $\sim 1300 \mathrm{~mL} / \mathrm{min}$ at the end of the drift tube thus flowing against the electric field gradient created by the resistors. The temperature of the IMS tube was maintained at $200^{\circ} \mathrm{C}$ during all experiments.

ESI solvent (methanol/water/acetic acid, 49.5/ 49.5/1) was introduced by a KD Scientific 210 syringe pump (New Hope, PA) at a flow rate of $3 \mu \mathrm{L} / \mathrm{min}$ into a $25 \mathrm{~cm}$ long, $50 \mu \mathrm{m}$ i.d. silica capillary. This capillary was then connected to a $10 \mathrm{~cm}$ long, $50 \mu \mathrm{m}$ i.d. silica capillary through a zero dead volume stainless steel internal fitting (Valco Instruments Co. Inc., Houston, $\mathrm{TX}$ ). The other end of the $10 \mathrm{~cm}$ capillary was centered $\sim 0.5 \mathrm{~cm}$ from the target screen of the APIMS. To generate electrospray, a positive high voltage of $3.00 \mathrm{kV}$ greater than that on the IMS target screen was applied at the internal fitting.

The time-of-flight mass spectrometer and supporting electronics were designed and constructed at Ionwerks Inc., Houston, TX. The APIMS was interfaced to the TOFMS through a $250 \mu \mathrm{m}$ aperture. A series of ion lenses guided the ions from the aperture to the extraction region of the time-of-flight analyzer. The ions were then extracted orthogonally, accelerated into the TOF drift tube, and detected by a microchannel plate detector (Burle Electro-Optics Inc., Sturbridge, MA) The detector signal, acquired by a time-to-digital converter (Ionwerks), was then processed by IDL Virtual machine based software. The mass spectrometer was calibrated in positive ion mode with different alkylamines and amino acids and optimized to a full width at half height resolution of $\sim 1000$ at an $m / z$ value of 108.09 for 2,4-lutidine.

\section{Chemicals and Solvents}

All carbohydrate standards [methyl- $\alpha$-D-galactopyranoside $(\alpha$-MeGal), methyl- $\beta$-D-galactopyranoside $(\beta$-MeGal), methyl- $\alpha$-D-glucopyranoside ( $\alpha$-MeGlc), methyl- $\beta$-Dglucopyranoside ( $\beta$-MeGlc), methyl- $\alpha$-D-mannopyranoside ( $\alpha$-MeMan), and methyl- $\beta$-D-mannopyranoside $(\beta$-MeMan), ribose, xylose, glucose, fructose, isomaltose, maltose, and sucrose] used in this study were purchased from Sigma-Aldrich, St. Louis, MO. The salts used in the experiments were also purchased from Sigma-Aldrich. High-performance liquid chromatography grade solvents (methanol, water, and acetic acid) were purchased from J. T. Baker (Phillipsburgh, NJ). ESI solvent was used to prepare 50 and $100 \mu \mathrm{M}$ solutions of sugar and salt, respectively, which were mixed in equal volumes when analyzed.

\section{IMS Theory}

IMS separates ions on the basis of the differences in their mobility $K\left(\mathrm{~cm}^{2} \mathrm{~V}^{-1} \mathrm{~s}^{-1}\right)$ while the ions are drifting through a drift gas in a weak homogenous electric field gradient. The mobility of an ion through the drift region of the IMS is given as the ratio of the average ion velocity $\left(v_{d}=L / t_{d}\right)$ to the applied electric field $(E=V / L)$

$$
K=\frac{v_{d}}{E}=\frac{L^{2}}{t_{d} V}
$$

where, $L$ is the length of the drift region in $\mathrm{cm}, t_{d}$ is the drift time in seconds (defined as the time an ion takes to travel through the drift region), and $V$ is the voltage applied to the ion gate in volts. Under different experimental conditions such as temperature, pressure, and electric field, variations in ion mobility values are observed and thus for comparative purposes "the reduced mobility value, $\mathrm{K}_{0}$ " of an ion is calculated using eq 2. Under different experimental conditions the $\mathrm{K}_{0}$ value of an ion remains constant with a standard deviation of $\pm 0.02 \mathrm{~cm}^{2} \mathrm{~V}^{-1} \mathrm{~s}^{-1}$ and is defined as follows:

$$
K_{0}=\left[\frac{L^{2}}{V t_{d}}\right]\left[\frac{273}{T}\right]\left[\frac{P}{760}\right]
$$

The mode and type of interactions between the ion and the drift gas depend on the configurational and conformational structure of both the ion and the drift gas and along with the collision dynamics defines the collision cross section of an ion. The average ion-neutral collision cross section $(\Omega)$ is measured by using the equation $[12]$ :

$$
\Omega=\left[\frac{3}{16 N_{A}}\right]\left[\frac{2 \pi}{\mu k T}\right]^{1 / 2}\left[\frac{z e}{K}\right]
$$

where $N_{A}$ is the number density of the drift gas in molecules per $\mathrm{cm}^{3}, \mu=[\mathrm{mM} /(\mathrm{m}+\mathrm{M})]$ is the reduced mass in kilograms of an ion of mass $m \mathrm{~g} / \mathrm{mol}$ and the neutral drift gas of $M \mathrm{~g} / \mathrm{mol}, k$ is Boltzmann's constant in $\mathrm{J} / \mathrm{K}, z$ is the number of the charge(s) on the ion, $e$ is the charge of one proton in Coulombs, and $\mathrm{K}$ is the mobility of the ion in $\mathrm{cm}^{2} \mathrm{~V}^{-1} \mathrm{~s}^{-1}$. Number density $N_{A}$ is calculated as $N_{A}=(\mathrm{P} / \mathrm{kT})$ where $\mathrm{P}$ is the ambient pressure in atmospheres, $\mathrm{k}$ is the Boltzmann's constant in $\mathrm{L}^{*} \mathrm{~atm} . / \mathrm{K}$, and $\mathrm{T}$ is the temperature in Kelvin.

Resolving power in IMS is defined by the ratio of the drift time to the peak width (in time) at half height $\left(R_{p}=t_{d} / w_{h}\right)$. Resolution in IMS is defined analogously to that in chromatography, which is the difference in the drift time of two ion mobility peaks divided by their average peak width. $\left[\mathrm{R}_{\mathrm{s}}=2\left(\mathrm{t}_{\mathrm{d} 2}-\mathrm{t}_{\mathrm{d} 1}\right) /\left(\mathrm{w}_{1}+\mathrm{w}_{2}\right)\right]$. Resolving power gives no information on the ability of two isomers to separate at all. For example, a TOFMS instrument could be described as having a high "resolving power", yet no "resolution" of isomers because they have the exact same $m / z$ value and thus cannot be differentiated by TOFMS. 
Table 1. Separation factors of monosaccharide methyl glycosides as metal ion complexes using ion mobility/mass spectrometry ${ }^{\mathrm{a}}$

\begin{tabular}{|c|c|c|c|c|c|c|}
\hline $\begin{array}{c}\text { Name of glycoside and } \\
\text { drift time }\left(t_{d}\right)^{b}\end{array}$ & $\begin{array}{c}\alpha-\mathrm{MeGal} \\
16.43\end{array}$ & $\begin{array}{c}\beta-\mathrm{MeGal} \\
15.96\end{array}$ & $\begin{array}{c}\alpha-\mathrm{MeGlc} \\
16.45\end{array}$ & $\begin{array}{c}\beta-\mathrm{MeGlc} \\
16.20\end{array}$ & $\begin{array}{c}\alpha \text {-MeMan } \\
15.70 \\
\end{array}$ & $\begin{array}{c}\beta-\text { MeMan } \\
15.55\end{array}$ \\
\hline \multicolumn{7}{|c|}{ Sodium adducts } \\
\hline$\alpha-\mathrm{MeGal}(16.43)$ & 1.00 & 1.03 & $\underline{1.00}^{\mathrm{c}}$ & 1.02 & 1.05 & 1.06 \\
\hline$\beta$-MeGal (15.96) & & 1.00 & $\overline{1.03}$ & 1.02 & 1.02 & 1.03 \\
\hline$\alpha$-MeGlc (16.45) & & & 1.00 & 1.02 & 1.05 & 1.06 \\
\hline$\beta$-MeGlc (16.20) & & & & 1.00 & 1.03 & 1.04 \\
\hline$\alpha$-MeMan (15.70) & & & & & 1.00 & $1.01^{\mathrm{c}}$ \\
\hline$\beta$-MeMan (15.55) & & & & & & 1.00 \\
\hline Name of glycoside and & $\alpha$-MeGal & $\beta$-MeGal & $\alpha$-MeGlc & $\beta$-MeGlc & $\alpha$-MeMan & $\beta$-MeMan \\
\hline drift time $\left(t_{d}\right)^{b}$ & 18.36 & 17.89 & 18.73 & 17.75 & 17.95 & 17.64 \\
\hline \multicolumn{7}{|c|}{ Cobalt acetate adducts } \\
\hline$\alpha-\mathrm{MeGal}(18.36)$ & 1.00 & 1.03 & 1.02 & 1.03 & 1.02 & 1.04 \\
\hline$\beta$-MeGal (17.89) & & 1.00 & 1.05 & ${\underline{1.01^{c}}}^{\mathrm{c}}$ & $1.00^{\mathrm{c}}$ & 1.02 \\
\hline$\alpha$-MeGIc (18.73) & & & 1.00 & $\overline{1.06}$ & $\overline{1.04}$ & 1.06 \\
\hline$\beta$-MeGIc (17.75) & & & & 1.00 & 1.02 & $1.01^{\mathrm{c}}$ \\
\hline$\alpha$-MeMan (17.95) & & & & & 1.00 & $\overline{1.02}$ \\
\hline$\beta$-MeMan (17.64) & & & & & & 1.00 \\
\hline
\end{tabular}

aSeparation factors are defined as the ratio of the slow drift compound/fast drift compound for any given pair of methyl glycosides, abbreviated as described in the text.

${ }^{b}$ Drift times $(\mathrm{ms})$ were recorded using $\mathrm{N}_{2}$ gas at $702 \mathrm{~mm} \mathrm{Hg}$ pressure, $425 \mathrm{~V} / \mathrm{cm}$, and were reproducible to $\pm 0.04 \mathrm{~ms}$.

'Underlined separation factors were of combined pairs where the difference in drift times of individual glycopyranosides was less than 0.2 ms, wherefore peaks seen in separations of mixtures will probably appear as broad unresolved peaks. Separation factors of 1.02 or greater will resolve two compounds, which will be observed as two discernable peaks.

\section{Results and Discussion}

\section{Resolution of Anomeric Isomers of Monosaccharide Methyl Glycosides}

To investigate whether APIMS could separate anomeric isomers of monosaccharides, methyl hexopyranosides were examined. Glycosides were used to avoid any potential interconversions between anomeric ( $\alpha$ - and $\beta$-) or ring (pyranose and furanose) configurations. Their analysis by ESI-APIMS-TOFMS showed that sodium adducts $(\mathrm{m} / \mathrm{z} 217)$ were the most abundant ion even when no sodium was added to the sugar solution. Less abundant ions identified as $\left[\mathrm{M}+\mathrm{H}_{3} \mathrm{O}\right]^{+}, \mathrm{m} / z$ 213, $[\mathrm{M}+\mathrm{H}]^{+}, m / z 195,\left[\mathrm{M}-\left(\mathrm{CH}_{3} \mathrm{O}\right)\right]^{+}, m / z 163,[\mathrm{M}+\mathrm{K}]^{+}$, $m / z 233$ and $\left[\mathrm{M}+\mathrm{K}+\mathrm{H}_{2} \mathrm{O}\right]^{+}, m / z 251$ were also detected. Ions at $\mathrm{m} / \mathrm{z} 195$ and 163 were the fragments of the protonated glycoside at $\mathrm{m} / \mathrm{z} 213$ generated at APIMS-TOFMS interface since they all had the same drift time. The average standard deviation in the drift times of ions for three runs was $0.04 \mathrm{~ms}$.

Solutions of methyl pyranosides with cobalt acetate showed that cobalt always adducted to the glycosides as a

Table 2. Effect of the nature of the metal ion on separation of anomeric pairs of methyl galactosides as metal ion complexes using ion mobility/mass spectrometry ${ }^{\mathrm{a}}$

\begin{tabular}{|c|c|c|c|c|c|c|c|}
\hline \multirow[b]{2}{*}{ Metal ion ${ }^{b}$} & \multirow[b]{2}{*}{ Complex } & \multirow[b]{2}{*}{$m / z^{e}$} & \multicolumn{2}{|c|}{ Drift time (ms) } & \multirow{2}{*}{$\begin{array}{l}\text { Separation } \\
\text { factor }^{c}\end{array}$} & \multicolumn{2}{|c|}{$\begin{array}{c}\text { Collision cross section } \\
\qquad\left(\AA^{2}\right)^{g}\end{array}$} \\
\hline & & & $\alpha$-MeGal & $\beta-\mathrm{MeGal}$ & & $\alpha$-MeGal & $\beta$-MeGal \\
\hline $\mathrm{Na}^{+}$ & {$[\mathrm{Na}+\mathrm{MeGall}]^{+}$} & 217 & 12.06 & 11.58 & 1.04 & 124 & 118 \\
\hline $\mathrm{Ag}^{+}$ & {$[\mathrm{Ag}+\mathrm{MeGal}]^{+}$} & $301^{f}$ & 12.95 & 12.31 & 1.05 & 131 & 124 \\
\hline $\mathrm{Co}^{+2}$ & {$\left[\mathrm{Co}\left(\mathrm{CH}_{3} \mathrm{COO}\right)+\mathrm{MeGal}\right]^{+}$} & 312 & 13.51 & 13.25 & 1.02 & 136 & 134 \\
\hline $\mathrm{Co}^{+2}$ & {$\left[\mathrm{Co}\left(\mathrm{C}_{5} \mathrm{H}_{7} \mathrm{O}_{2}\right)+\mathrm{MeGal}\right]^{+}$} & $352^{d}$ & 14.31 & 14.08 & 1.02 & 144 & 141 \\
\hline $\mathrm{Cu}^{+2}$ & {$\left[\mathrm{Cu}\left(\mathrm{CH}_{3} \mathrm{COO}\right)+\mathrm{MeGaI}\right]^{+}$} & $316^{f}$ & 13.40 & 13.10 & 1.03 & 135 & 132 \\
\hline $\mathrm{Ca}^{+2}$ & {$\left[\mathrm{Ca}\left(\mathrm{CH}_{3} \mathrm{COO}\right)+\mathrm{MeGal}\right]^{+}$} & $293^{f}$ & 14.62 & 14.44 & 1.01 & 148 & 146 \\
\hline $\mathrm{Hg}^{+2}$ & {$\left[\mathrm{Hg}\left(\mathrm{CH}_{3} \mathrm{COO}\right)+\mathrm{MeGal}\right]^{+}$} & $455^{f}$ & 13.70 & 13.50 & 1.01 & 136 & 134 \\
\hline $\mathrm{Pb}^{+2}$ & {$\left[\mathrm{~Pb}\left(\mathrm{CH}_{3} \mathrm{COO}\right)+\mathrm{MeGal}\right]^{+}$} & $461^{f}$ & 13.28 & 12.44 & 1.07 & 133 & 124 \\
\hline $\mathrm{Pb}^{+2}$ & {$\left[\mathrm{~Pb}\left(\mathrm{C}_{5} \mathrm{H}_{7} \mathrm{O}_{2}\right)^{\mathrm{d}}+\mathrm{MeGal}\right]^{+}$} & $501^{f}$ & 14.43 & 14.20 & 1.02 & 143 & 141 \\
\hline
\end{tabular}

aDrift times were recorded using $\mathrm{N}_{2}$ gas at $700 \mathrm{~mm} \mathrm{Hg}$ pressure, $562 \mathrm{~V} / \mathrm{cm}$, and were reproducible to $\pm 0.04 \mathrm{~ms}$.

bSalts were present with acetate counterions unless otherwise noted.

'Separation factors are defined as the ratio of the slow drift compound/fast drift compound for anomeric pairs of methyl galactosides.

${ }^{\mathrm{d}}$ Salt contained the acetylacetonate counterion.

${ }^{\mathrm{e}} \mathrm{m} / \mathrm{z}$ of most abundant ion.

${ }^{f}$ Multiple peaks corresponding to isotopic distribution observed in $\mathrm{m} / \mathrm{z}$ domain.

${ }^{\mathrm{g}}$ Collision cross section calculated using eq 3. 
singly charged cobalt acetate, $\left[\mathrm{M}+\mathrm{Co}\left(\mathrm{CH}_{3} \mathrm{COO}\right)\right]^{+}$, observed at $\mathrm{m} / \mathrm{z} 312$. Background ions and clusters solely resulting from the addition of cobalt acetate to the ESI solvent were also identified as $\left[\mathrm{Co}\left(\mathrm{CH}_{3} \mathrm{COO}\right)_{2} \mathrm{H}\right]^{+}, \mathrm{m} / \mathrm{z}$ $178,\left[\mathrm{Co}\left(\mathrm{CH}_{3} \mathrm{COO}\right)_{2} \mathrm{H}_{3} \mathrm{O}\right]^{+}, \mathrm{m} / \mathrm{z} 196,\left[\mathrm{Co}_{2}\left(\mathrm{CH}_{3} \mathrm{COO}\right)_{3}\right]^{+}$, $\mathrm{m} / \mathrm{z} 295$, and $\left[\mathrm{Co}_{2}\left(\mathrm{CH}_{3} \mathrm{COO}\right)_{4} \mathrm{H}_{3} \mathrm{O}\right]^{+}, \mathrm{m} / z$ 373. Anomeric methyl galactopyranosides were also examined in the presence of $\mathrm{Ag}^{+}, \mathrm{Ca}^{+2}, \mathrm{Cu}^{+2}, \mathrm{Hg}^{+2}$, and $\mathrm{Pb}^{+2}$ as the acetate salts, and $\mathrm{Co}^{+2}$ and $\mathrm{Pb}^{+2}$ as the acetylacetonate salts. Results with methyl glycosides run individually and as mixtures of anomeric and other isomeric pairs are described in the following sections and are summarized $^{\circ}$ in $^{\circ}$ Tables $^{\circ} 1,{ }^{\circ},{ }^{\circ}$ and $^{\circ} 3$.

\section{Methyl- $\alpha-D$-Galactopyranoside and Methyl- $\beta$-D-Galactopyranoside}

A two-dimensional contour plot of an APIMS-MS experiment performed using $\mathrm{N}_{2}$ as the drift gas with a mixture of anomeric methyl galactosides is shown in Figure $^{\circ} 1 .^{\circ}$ Peaks $^{\circ}$ at $^{\circ} \mathrm{m} / z$ 217 ${ }^{\circ}$ Figure $\left.^{\circ} 1 \mathrm{a}\right)^{\circ}$ were $^{\circ}$ sodium adducts ${ }^{\circ}$ and ${ }^{\circ}$ peaks ${ }^{\circ}$ at $^{\circ} \mathrm{m} / \mathrm{z} 312^{\circ}\left(\text { Figure }^{\circ} 1 \mathrm{~b}\right)^{\circ}$ were ${ }^{\circ}$ cobalt acetate adducts. Although the separation was better between sodium adducts, APIMS afforded high enough resolution with either salt adduct to enable anomers to be unambiguously identified. Drift times of the methyl galactosides run individually as either sodium or cobalt acetate $^{\circ}$ adducts $^{\circ}$ are $^{\circ}$ presented $^{\circ}$ in $^{\circ} \operatorname{Table}^{\circ} 1$.

\section{Methyl- $\alpha$-Glucopyranoside and Methyl- $\beta$-Glucopyranoside}

A 2D IMS-MS spectrum of a mixture of methyl- $\alpha$ - and $\beta$-glucopyranosides illustrating the separation of anomers as sodium and cobalt acetate adducts is shown in Figure ${ }^{\circ}$, ${ }^{\circ}$ again ${ }^{\circ}$ using ${ }^{\circ} \mathrm{N}_{2}$ as the drift gas. Drift times of the anomers run individually as either adduct are

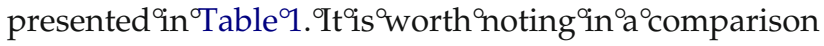
of ${ }^{\circ}$ Figures ${ }^{\circ} 1^{\circ}$ and $2^{\circ}$ that ${ }^{\circ}$ the ${ }^{\circ}$ sodium adducts ${ }^{\circ}$ of ${ }^{\circ}$ anomeric methyl glucopyranosides were only partially separated by IMS but the cobalt acetate adducts were baseline separated, whereas the opposite was the case for the methyl galactopyranosides.

\section{Methyl- $\alpha$-D-Mannopyranoside and Methyl- $\beta$-D-Mannopyranoside}

Like the methyl-glucopyranoside and -galactopyranoside anomeric pairs, the methyl-mannopyranosides were ${ }^{\circ}$ also ${ }^{\circ}$ resolved ${ }^{\circ}$ by $^{\circ}$ APIMS-MS $^{\circ}\left(\right.$ Table $\left.^{\circ} 1\right) .{ }^{\circ} \mathrm{Using}^{\circ} \mathrm{N}_{2}$ gas, the sodium adducts were not resolved (or two peaks were just barely discernable) and the $[\mathrm{M}+$ $\left.\mathrm{Co}\left(\mathrm{CH}_{3} \mathrm{COO}\right)\right]^{+}$ion peaks were only partially resolved. Better separation of this anomeric pair was achieved using different drift gases as shown later in this article.

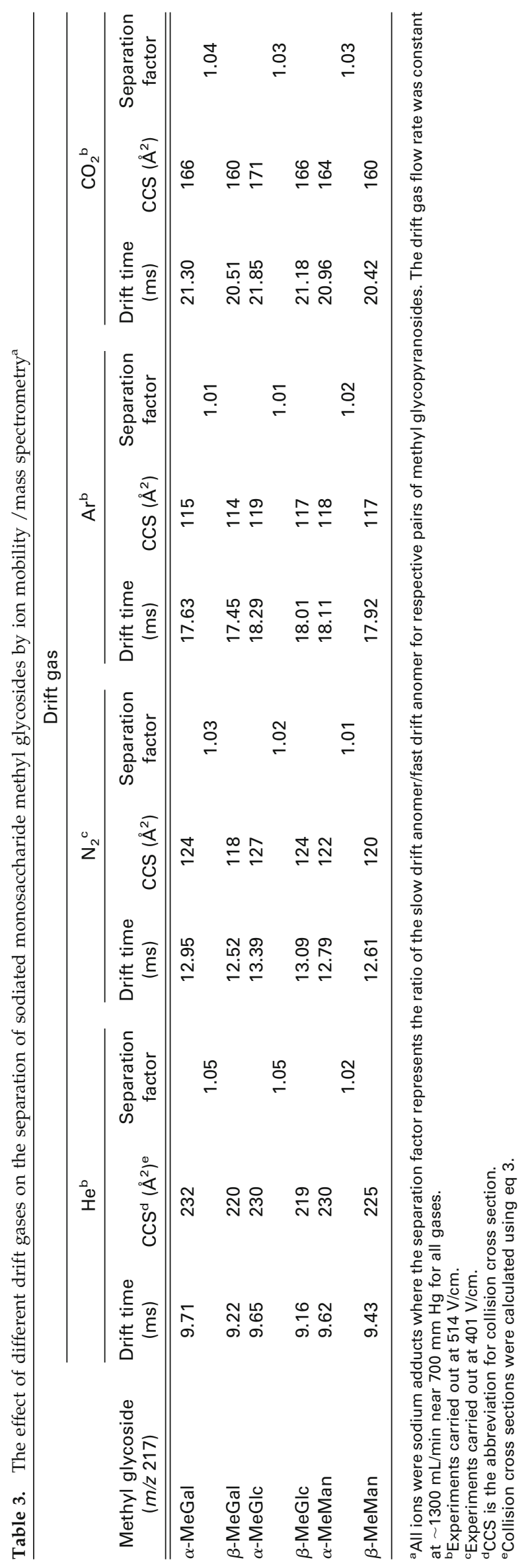




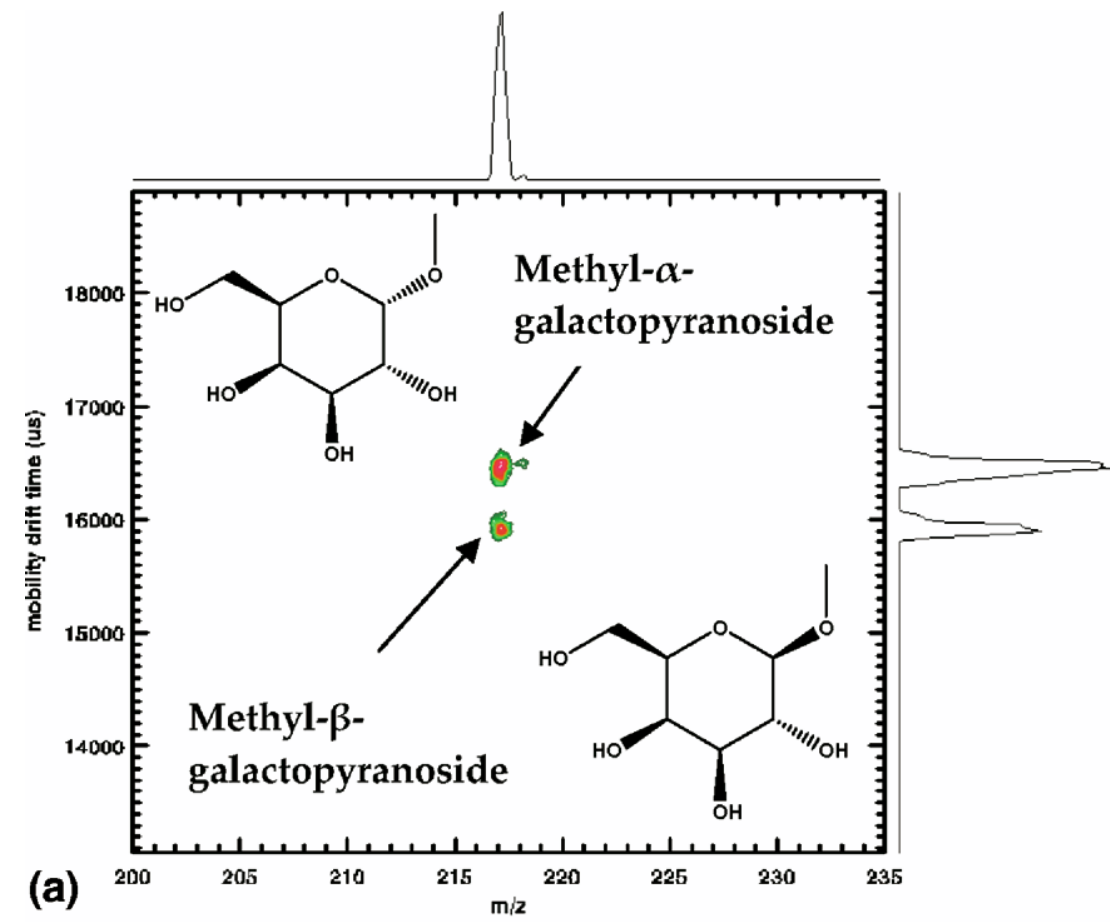

(a)

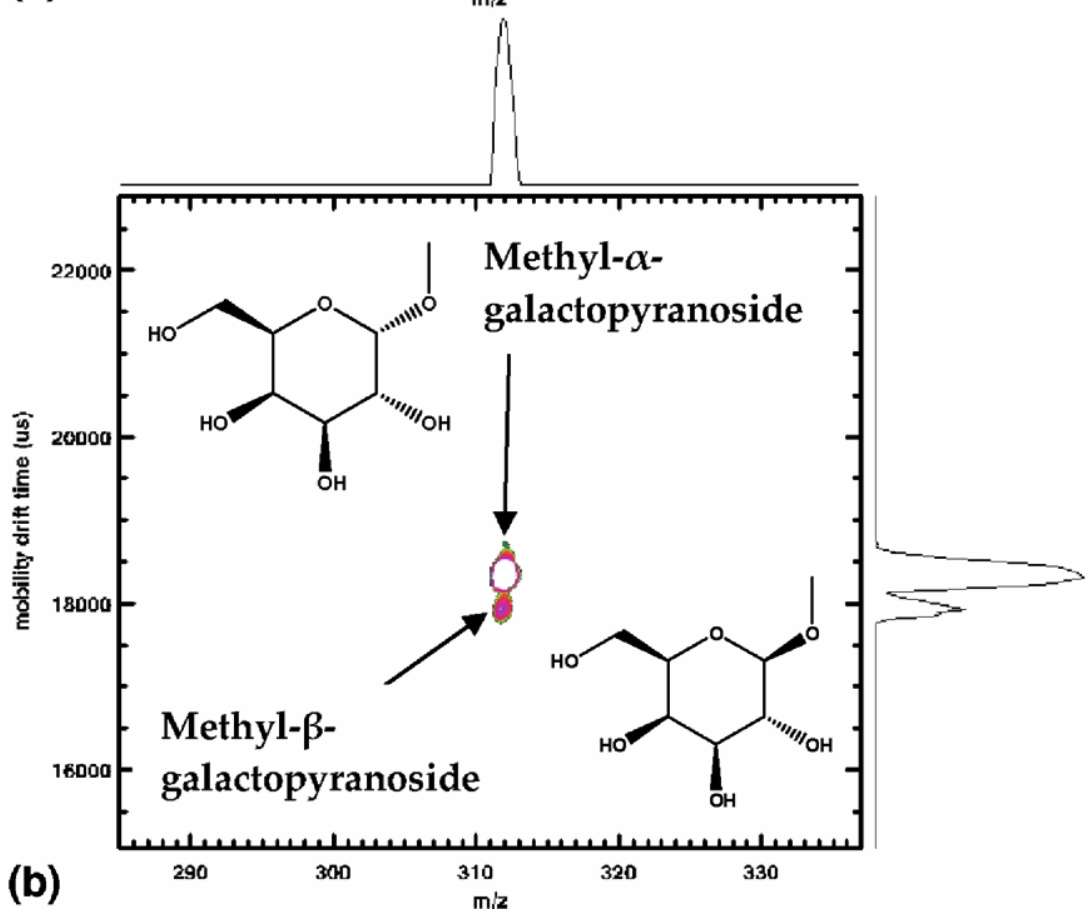

Figure 1. Two-dimensional IMS-MS spectra of a mixture of methyl- $\alpha$-and $\beta$-D- galactopyranosides showing the separation $\left(\mathrm{N}_{2}\right.$ drift gas) of the sodium adducts at $m / z 217$ (a) and the cobalt acetate adducts at $m / z 312$ (b). Drift times of methyl- $\alpha$ and $\beta$-D-galactopyranosides run individually under these ${ }^{\circ}$ conditions $^{\circ}$ are ${ }^{\circ}$ presented ${ }^{\circ}{ }^{\circ}{ }^{\circ} T_{a b l e} 1$.

Resolution of Isomeric Monosaccharide Methyl Glycosides Differing in the Stereochemistry at Positions Other Than the Anomeric Carbon

Figure $^{\circ} 3^{\circ}$ shows $^{\circ}$ separations $^{\circ}$ of $^{\circ}$ two $^{\circ}$ sets $^{\circ}$ of ${ }^{\circ}$ methyl glycosides varying in the stereochemistry of a single asymmetric carbon other than at the anomeric position.
For example, $\alpha$-MeGlc and $\alpha$-MeMan, two epimers that vary only in the asymmetry at the C2-position, were baseline resolved as sodium adducts using $\mathrm{N}_{2}$ as the $\operatorname{drift}^{\circ} \operatorname{gas}^{\circ}$ (Figure ${ }^{\circ} 3$ a). ${ }^{\circ}$ Similarly, ${ }^{\circ} \beta-\mathrm{MeGal}^{\circ}$ and ${ }^{\circ} \beta$-MeGlc, epimeric ${ }^{\circ}$ at ${ }^{\circ}$ the ${ }^{\circ} \mathrm{C} 4$-position, ${ }^{\circ}$ were ${ }^{\circ}$ resolved $^{\circ}$ (Figure ${ }^{\circ} 3 \mathrm{~b}$ ). The drift times of the individual monosaccharides and the $e^{\circ}$ experimental ${ }^{\circ}$ conditions $^{\circ}$ are $^{\circ}$ reported $^{\circ}$ in $^{\circ}$ Table $^{\circ} 1$. 


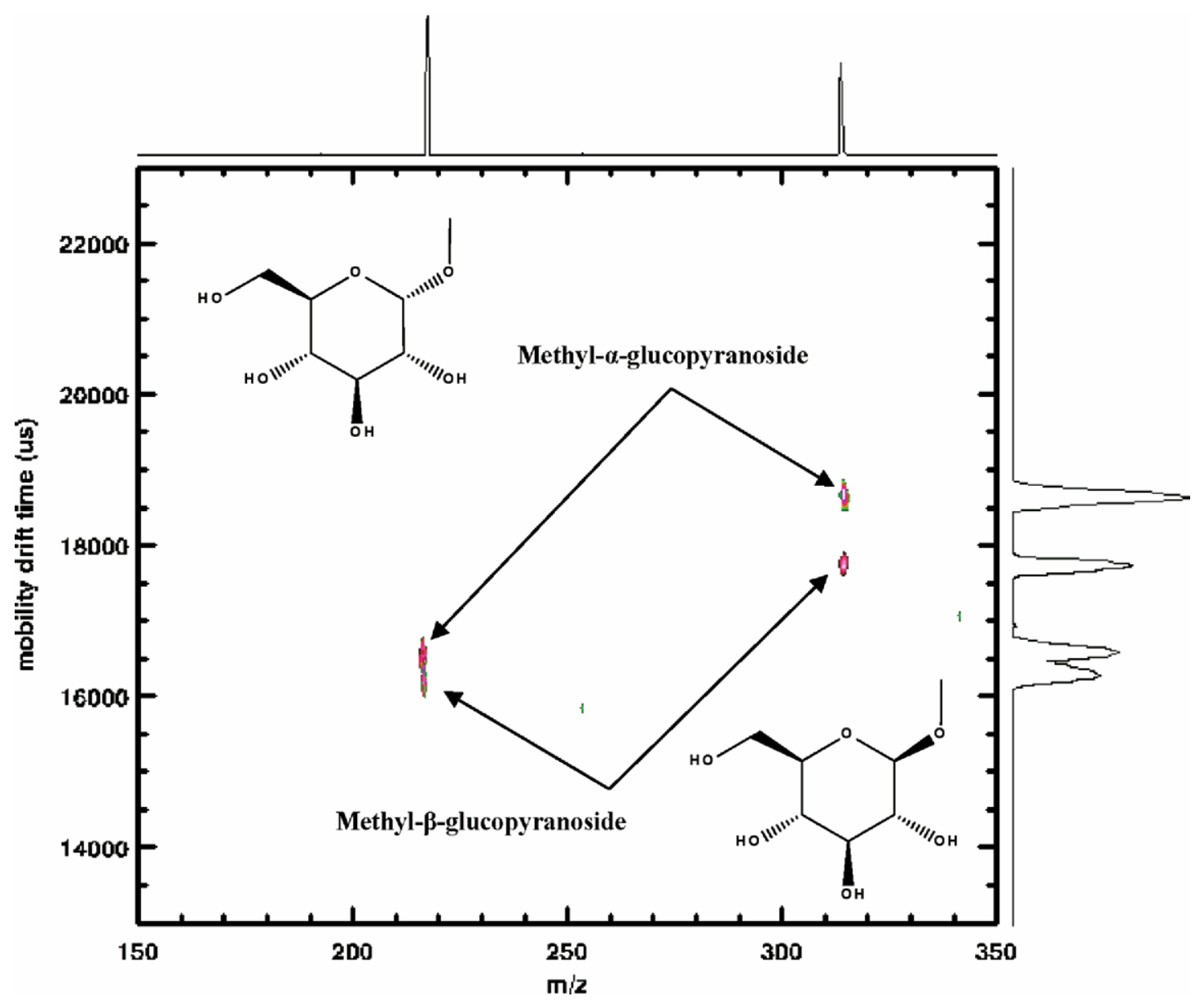

Figure 2. Two-dimensional IMS-MS plot of a mixture of methyl- $\alpha$ - and $\beta$-D-glucopyranosides $\left(\mathrm{N}_{2}\right.$ drift gas). Sodium adducts of the anomers at $\mathrm{m} / \mathrm{z} 217$ were partially separated in the mobility dimension and baseline separated as cobalt acetate adducts at $m / z$ 312. Drift times of sodium and cobalt acetate adducts of methyl- $\alpha$ - and $\beta$-D-glucopyranosides run individually are presented in Table ${ }^{\circ} 1$.

Note that conditions for the separations shown in Figure $^{\circ} 3^{\circ}$ were $^{\circ}$ different $^{\circ}$ than $^{\circ}$ reported $^{\circ}{ }^{\circ}{ }^{\circ}$ Table $^{\circ} 1^{\circ}$ hence different drift times were observed.

Further $^{\circ}$ analysis $^{\circ}$ of $^{\circ}$ the $^{\circ}$ data $^{\circ}$ listed $^{\circ}$ in $^{\circ}$ Table $^{\circ} 1$ revealed the following: (1) adducts of $\alpha$-methyl glycosides with either sodium or cobalt acetate, without exception, drifted longer times than the $\beta$-anomers. (2) Cobalt acetate adducts invariably had longer drift times than the sodium adducts, and (3) drift time differences between anomers were dependent on both the stereochemistry of the sugars and the nature of adducts.

Based on drift times of the cobalt acetate adducts $\left(\text { Table }^{\circ} 1\right)^{\circ}$ and $^{\circ}$ the ${ }^{\circ}$ inverse ${ }^{\circ}$ relationship ${ }^{\circ}$ between $^{\circ}$ ion mobility and collision cross section (eq 3), the collision cross sections (CCS) of the anomer-cobalt acetate adducts followed the trend of $\alpha$-MeGlc $>\alpha$-MeGal $>$ $\alpha$-MeMan $>\beta$-MeGal $>\beta$-MeGlc $>\beta$-MeMan. The CCS of the sodium adducts, based on their drift times as ${ }^{\circ}$ listed ${ }^{\circ}$ in ${ }^{\circ}$ Table $^{\circ} 1,{ }^{\circ}$ followed ${ }^{\circ}$ the ${ }^{\circ}$ trend ${ }^{\circ}$ of $\alpha-$ MeGlc $^{\circ}>$ $\alpha$-MeGal $>\beta$-MeGlc $>\beta$-MeGal $>\alpha$-MeMan $>$
$\beta$-MeMan. The measured CCS must reflect differences in the overall structures of the methyl glycosides as coordinated ion complexes; detailed calculations of these structures are currently under investigation.

Separation factors between all possible combinations of the glycopyranosides were generated from measured drift times of the sodium adducts of anomers of all ${ }^{\circ}$ methy $l^{\circ}$ glycosides $^{\circ}$ studied $^{\circ}\left(\operatorname{Table}^{\circ} 1\right) .{ }^{\circ}$ Based $^{\circ}$ on ${ }^{\circ}$ the experimentally determined criterion under the experimental conditions to define "separation" (0.2 ms drift time difference), underlined glycoside combinations ${ }^{\circ}$ in $^{\circ}$ Table $^{\circ} 1^{\circ}$ indicate $^{\circ}$ pairs $^{\circ}$ of $^{\circ}$ glycopyranosides that could not be resolved with a resolution greater than 0.5 , or two peaks were not discernable but appeared as one broad coalesced peak. Excluding the same pyranoside combinations it was concluded that

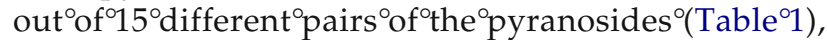
13 can be separated as sodium adducts. Similarly, 12 of the 15 pairs can be separated as cobalt acetate adducts. Notably the pairs not separated as sodium 

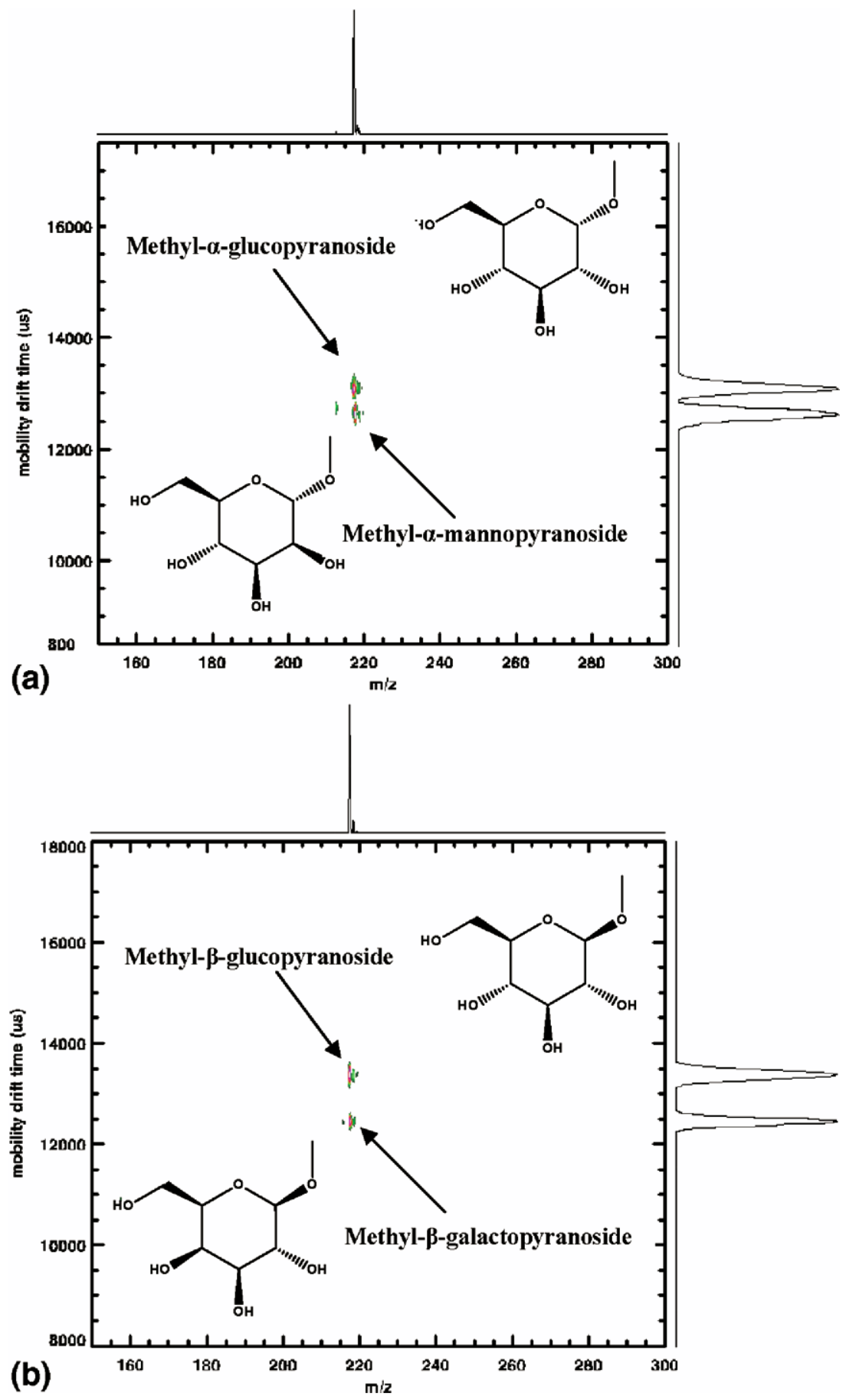

Figure 3. Two-dimensional IMS-MS plots illustrating the separation of epimers as sodium adducts at $m / z 217$ ( $\mathrm{N}_{2}$ drift gas). (a) $\alpha$ MeGlc and $\alpha$-MeMan; (b) $\beta$-MeGlc and $\beta$-MeGal. Measurements were performed at an electric field of $514 \mathrm{~V} / \mathrm{cm}$ and $699 \mathrm{~mm} \mathrm{Hg}$ pressure and drift times of the glycosides run $^{\circ}$ separately ${ }^{\circ}$ under $^{\circ}$ different $^{\circ}$ conditions $^{\circ}$ are ${ }^{\circ}$ listed ${ }^{\circ}{ }^{\circ}{ }^{\circ} \mathrm{Table}^{\circ} 1$.

adducts were separated as their $\left[\mathrm{M}+\mathrm{Co}\left(\mathrm{CH}_{3} \mathrm{COO}\right)\right]^{+}$ counterparts, thus all 15 pairs can be separated as either of the two adducts. Resolution was limited in part to the use of a $0.2 \mathrm{~ms}$ pulse width for these particular experiments. Higher resolution could be achieved by operation at more narrow IMS pulse widths $(0.1 \mathrm{~ms})$, at the practical expense of loss of sensitivity.
Given the results using different metal ions above, and owing to the tremendous number of potential isomeric variants in the analysis of complex carbohydrates that might require greater experimental flexibility to obtain physical resolution, experiments were conducted to investigate the effects of additional cations and cation complexes and different drift gases on the separation of carbohydrate isomers, detailed in the following sections. 


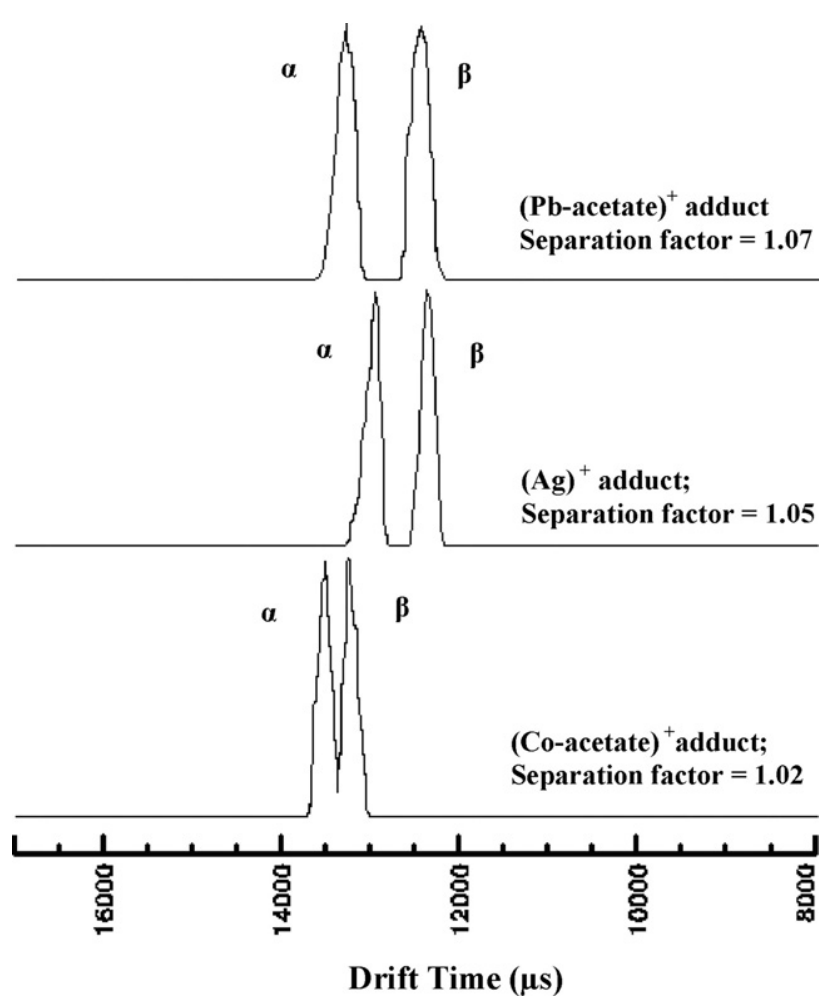

Figure 4. IMS ${ }^{\circ}$ spectra ${ }^{\circ} f^{\circ} \alpha-{ }^{\circ}$ and $^{\circ} \beta-\mathrm{MeG}$ al 9 illustrating ${ }^{\circ}$ the ${ }^{\circ}$ effect ${ }^{\circ}$ of various cations on separation factor. Ion identity and mobility values ${ }^{\circ}$ are $^{\circ}$ listed ${ }^{\circ}$ in $^{\circ}$ Table $^{\circ} 2$.

\section{Effects of Additional Cations on Separation of One Selected Anomeric Pair of Glycosides, $\alpha$ - and $\beta$-Methylgalactopyranosides}

Figure 4 9illustrates ${ }^{\text {the }}$ gas-phase ${ }^{\circ}$ separation ${ }^{\circ}$ of $^{\circ} \alpha-\mathrm{MeGal}$ and $\beta$-MeGal when complexed with three different cations or cation complexes, $\left[\mathrm{M}+\mathrm{Co}\left(\mathrm{CH}_{3} \mathrm{COO}\right)\right]^{+},[\mathrm{M}$ $+\mathrm{Ag}]^{+}$, or $\left[\mathrm{M}+\mathrm{Pb}\left(\mathrm{CH}_{3} \mathrm{COO}\right)\right]^{+}$. As indicated, the nature of the cation has marked affects on separation of anomeric pairs, varying from separation factors of 1.01 to ${ }^{\circ} 1.07^{\circ}\left(\mathrm{Table}^{\circ} 2\right){ }^{\circ}{ }^{\circ} \mathrm{Some}^{\circ}$ of $^{\circ}$ these ${ }^{\circ}$ differences $^{\circ}$ may $^{\circ}$ result from fundamental differences in coordination of counterion species. Singly-charged metals, for example, $\left(\mathrm{Na}^{+}, \mathrm{Ag}^{+}\right)$invariably adducted with methyl glycosides as naked ions but doubly-charged ions yielded singly charged adducts that also included an acetate or acetylacetonate anion. While we have not explored a wide variety of counterions as yet, it was evident that changing the acid counterion can also endow the ion complexes with unique properties that alter their separation. This was observed, for instance, in the comparison of $\left[\mathrm{M}+\mathrm{Pb}\left(\mathrm{CH}_{3} \mathrm{COO}\right)\right]^{+}$and $\left[\mathrm{M}+\mathrm{Pb}\left(\mathrm{C}_{2} \mathrm{H}_{5} \mathrm{O}_{2}\right)\right]^{+}$adducts having separation factors of 1.07 and 1.02, respectively ${ }^{\circ}\left(\right.$ Table $\left.^{\circ} 2\right)$.

\section{Different Drift Gases Markedly Affect the Separation of Isomeric Methyl Glycosides}

While nitrogen is one of the most common drift gases used in IMS, the variation of drift times with polariz- ability of the drift gas has been reported for a number of analytes using different gases or mixtures including air, nitrogen, helium, argon, $\mathrm{CO}_{2^{\circ}}$ and ${ }^{\circ} \mathrm{SF}_{6}{ }^{\circ}[35-38] .{ }^{\circ}$ General conclusions drawn from these reports are that the polarizability of the drift gas can dramatically affect not only overall drift times but also the order of arrival times ${ }^{\circ}$ for $^{\circ}$ various $^{\circ}$ molecules $^{\circ}[35]$.

As mentioned earlier, $\alpha$-MeMan and $\beta$-MeMan as sodium adducts were not resolved using $\mathrm{N}_{2}$ gas and a pulse ${ }^{\circ}$ width ${ }^{\circ}$ of $^{\circ} 0.2^{\circ} \mathrm{ms}^{\circ}\left(\right.$ Table $\left.^{\circ} 1\right) .{ }^{\circ}$ Studies ${ }^{\circ}$ were ${ }^{\circ}$ therefore performed with drift gases of varying polarizability which included $\mathrm{N}_{2}, \mathrm{CO}_{2}, \mathrm{Ar}$, and He. In these experiments the flow rate of the drift gases was maintained identically for all gases by adjusting the flow rate meter to the flowrate of different gases going through it. Two-dimensional IMS-MS spectra of $\alpha$-MeMan and $\beta$-MeMan as sodium adducts at $m / z 217$ are shown in Figure $^{\circ} 5,{ }^{\circ}$ at $^{\circ}$ an $^{\circ} \mathrm{IMS}^{\circ}$ pulse ${ }^{\circ}$ width $^{\circ}$ of $^{\circ} 0.2 \mathrm{~ms}^{\circ}$ using $^{\circ} \mathrm{CO}_{2}$ $\left(\text { Figure }^{\circ} 5 \mathrm{a}\right)^{\circ}$ and $^{\circ} \mathrm{N}_{2^{\circ}}\left(\text { Figure }^{\circ} 5 b\right)^{\circ}$ as $^{\circ}$ drift $^{\circ}$ gases. ${ }^{\circ}$ Baseline separation was achieved when $\mathrm{CO}_{2}$ was used. As shown ${ }^{\circ}$ in $^{\circ} \mathrm{Table}^{\circ} 3$, ${ }^{\circ}$ the ${ }^{\circ}$ separation ${ }^{\circ}$ of $^{\circ}$ two $^{\circ}$ isomers $^{\circ}$ using the different drift gases $\mathrm{He}, \mathrm{Ar}, \mathrm{N}_{2}$ or $\mathrm{CO}_{2}$ was often dramatically affected in unpredictable ways. For example, the separation factors of the methyl-galactopyranosides ranged from $1.01(\mathrm{Ar})$ to $1.05(\mathrm{He})$. From the purely practical analytical perspective, however, the use of different drift gases imparts another level of flexibility ${ }^{\circ}{ }^{\circ}$ separation $^{\circ}$ of $^{\circ}$ carbohydrate ${ }^{\circ}$ isomers. ${ }^{\circ}$ Figure 6 shows the linear relationship between the measured collision cross sections of adducts and polarizability of drift gases for $\alpha$ - and $\beta$ - MeMan, MeGal, and MeGlc. Extrapolation of this linear relationship provides the zero polarizability collision cross section that can be used in an ab initio calculations for modeling purposes.

\section{Separation of Isomers of Reducing Sugars}

In Figure 7 the IMS profile'is shown of reducing glucose as a sodium adduct using either $\mathrm{N}_{2}$ or $\mathrm{CO}_{2}$ as drift gas. It is clearly evident from all three traces that glucose has at least three observable isomeric forms that resolve in the gas phase as sodium adducts. Increased resolution with lowered pulse width is also clearly evident in the figure. Other reducing sugars also typically separated into $^{\circ}$ more $^{\circ}$ than $^{\circ}$ one $^{\circ}$ gas-phase $^{\circ}$ form ${ }^{\circ}\left(\text { Table }^{\circ} 4\right)^{\circ}$ except ribose, which was virtually entirely one IMS peak. Both the nature of the drift gas and the ion mobility pulse

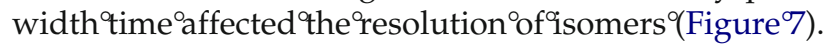
One caveat with reducing sugars as mentioned previously is that they can exist in multiple anomeric and cyclic forms in solution. During the process of electrospray ionization these isomeric forms might produce adduct ions in an unpredictable fashion, or potentially might adduct at more than one site with a given ion. In addition, considering the complexity of the electrospray process, the sugars themselves might interconvert to yield ratios of the different configurations that are not observed, for instance, by NMR in solution. Furthermore, the observation of one peak as in the case of 

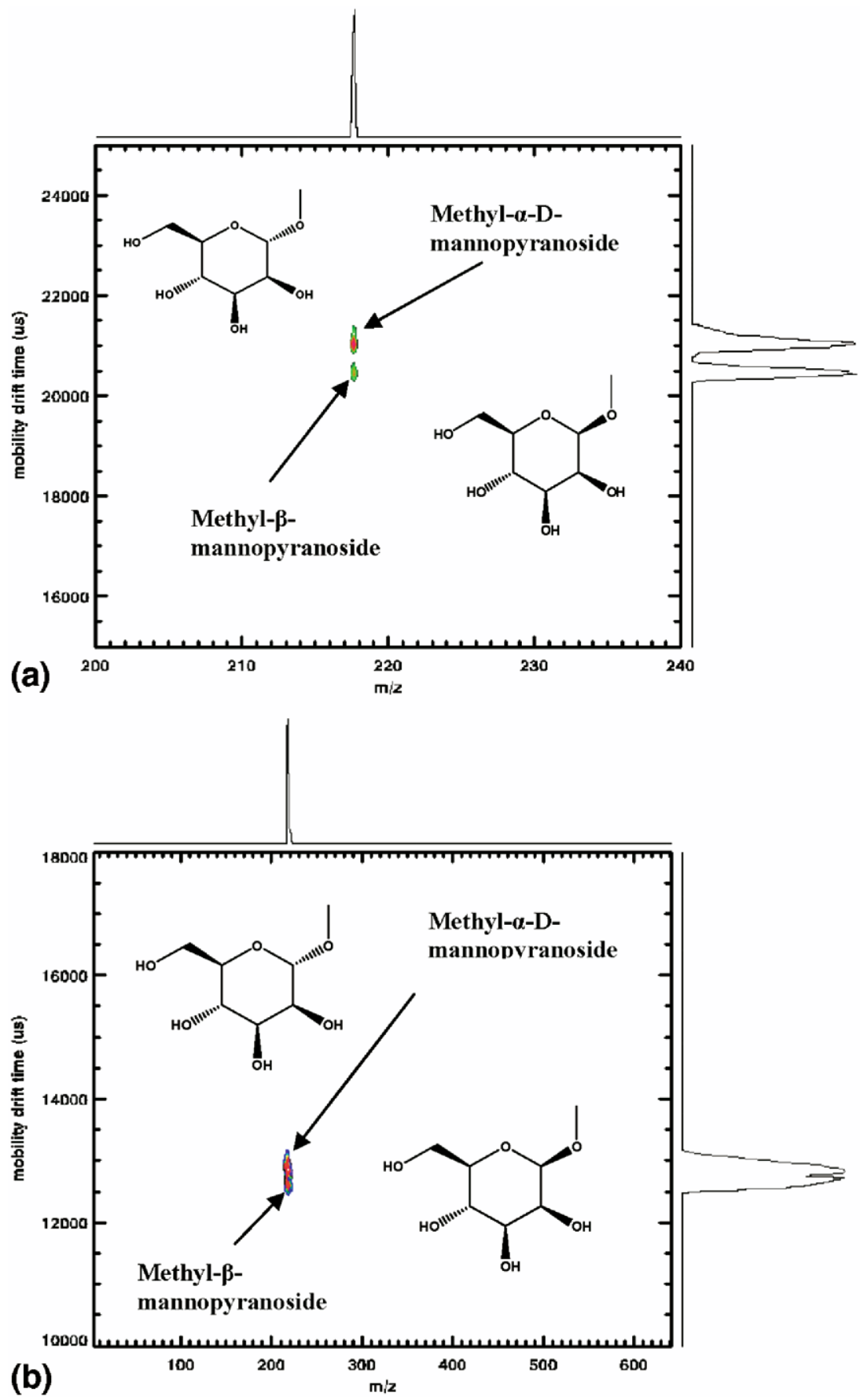

Figure 5. 2D IMS-MS spectra illustrating the baseline separation of $\alpha$ - and $\beta$-anomers of methylmannopyranoside as sodium adducts at $m / z 217$ when carbon dioxide was used as the drift gas (a). The same anomers were barely resolved as sodium adducts with nitrogen as the drift gas (b). The above measurements were performed at $514 \mathrm{~V} / \mathrm{cm}$ and $699 \mathrm{~mm} \mathrm{Hg}$ pressure.

ribose could be due to coincidental co-migration of two or more anomeric/cyclic/adduct variants.

The data illustrate the capability of APIMS to separate different forms of reducing monosaccharides having different anomeric configurations and possibly different ring forms. Moreover, the IMS profiles observed for individual sugars are unique at a given $\mathrm{m} / \mathrm{z}$ and can rapidly provide additional information orthogonal to MS for identification of a monosaccharide, because monosaccharide dissociation patterns are often very similar. However, interpretation of the actual molecular complexes involved will require much more detailed studies involving calculations and potentially studies with other model sugar glycosides that could give rise to single gas-phase species through dissociation. It is worth noting that for all the methyl glycosides examined $^{\circ}$ as $^{\circ}$ adducts $^{\circ}$ with $^{\circ}$ several $^{\circ}$ different $^{\circ}$ metal $^{\circ}$ ions ${ }^{\circ}(\mathrm{Ta}-$ bles $^{\circ} 1,{ }^{\circ} 2,{ }^{\circ}$ and $\left.^{\circ} 3\right),{ }^{\circ}$ only ${ }^{\circ}$ single ${ }^{\circ}$ peaks $^{\circ}$ were ${ }^{\circ}$ observed 


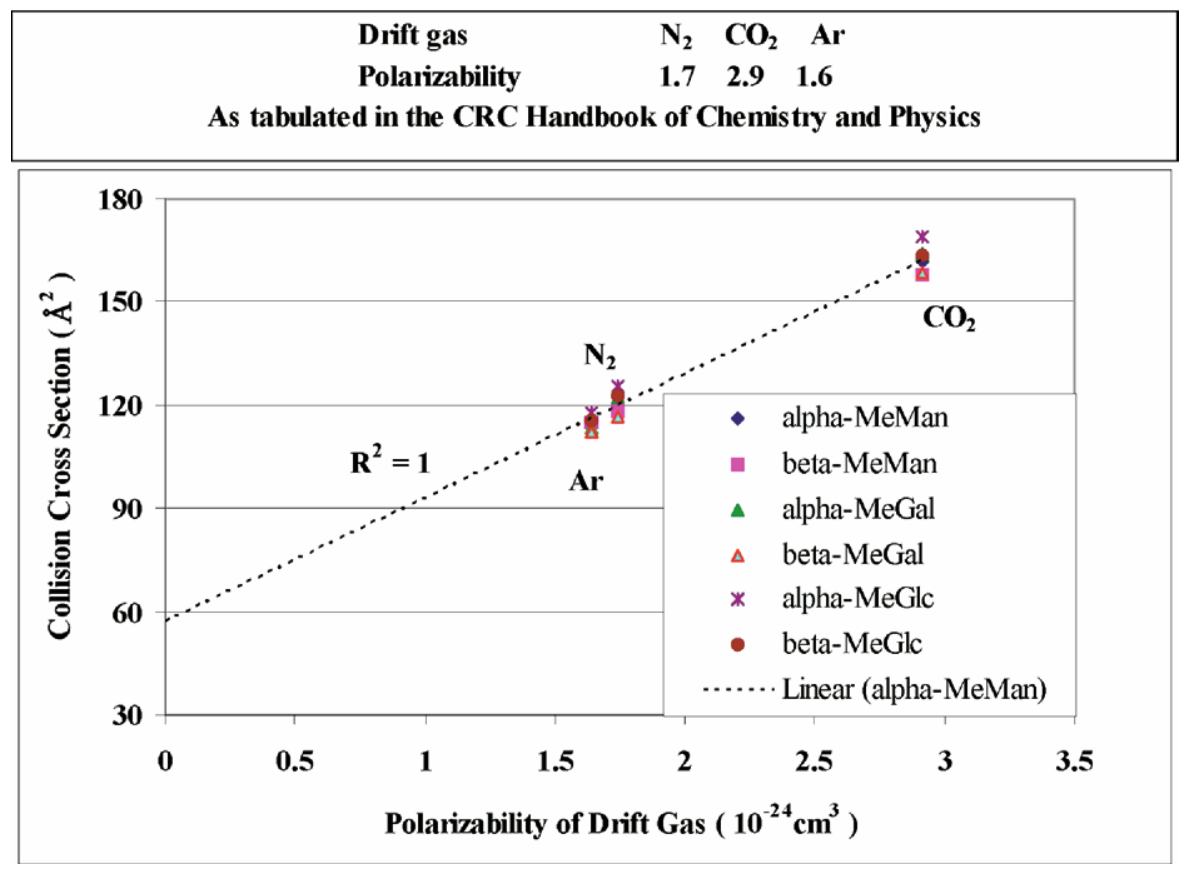

Figure 6. Variation in the ion collision cross section with the polarizability of drift gases for the $\alpha$ and $\beta$-anomers of MeMan, MeGal, and MeGlc. A linear relationship between drift gas polarizability and collision cross section was observed for all the anomers. Collision cross sections for pyranosides in $^{\circ}$ different $^{\circ} \mathrm{drift}^{\circ}$ gases $^{\circ}$ are $^{\circ}$ listed $^{\circ}$ in $^{\circ}$ Table $^{\circ} 3$.

whereas for reducing sugars, multiple peaks were the typical scenario. This argues that in most cases, for
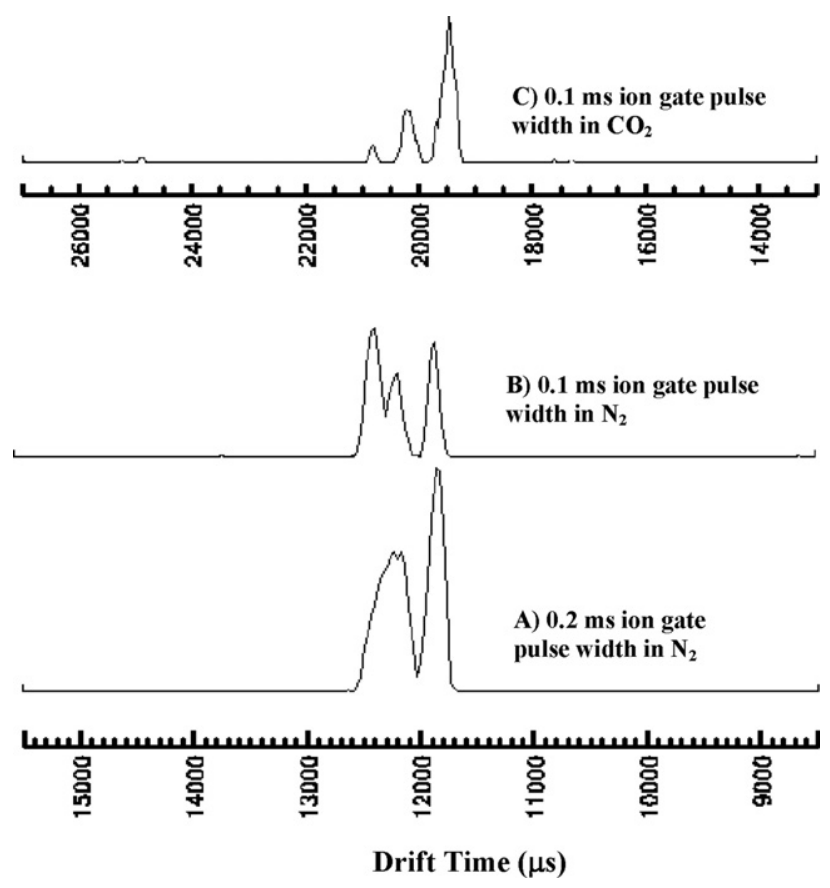

Figure 7. IMS-MS spectra of glucose as a sodium adduct at $\mathrm{m} / \mathrm{z}$ 203. (a) Glucose with nitrogen as drift gas and $0.2 \mathrm{~ms}$ IMS pulse width, (b) glucose with nitrogen as drift gas and $0.1 \mathrm{~ms}$ IMS pulse width, and (c) glucose with carbon dioxide as drift gas and $0.1 \mathrm{~ms}$ IMS pulse width. Separation between isomeric forms of glucose increased with decreased pulse width and increased drift gas polarizability. reducing monosaccharides, the different forms are probably anomeric/cyclic variants rather than adducts at multiple locations for one given cyclic form/anomer, although the latter certainly cannot be ruled out.

\section{Separation of Disaccharides and Effects of the Reducing Sugar}

We previously demonstrated that small disaccharidealditols derived from glycoproteins and some trisaccharides (two of them nonreducing) could be separated by APIMS-MS $[31] .{ }^{\circ}$ The $^{\circ}$ compounds $^{\circ}$ were ${ }^{\circ}$ in ${ }^{\circ}$ part ${ }^{\circ}$ selected because they resulted in single peaks, and borohydride reduction of reducing sugars to alditols prevented the effects of alternative anomers/cyclization on ion mobility ${ }^{\circ}$ that ${ }^{\circ}$ thereby ${ }^{\circ}$ simplifies ${ }^{\circ}$ the ${ }^{\circ}$ analyses. ${ }^{\circ}{ }^{\circ}{ }^{\circ}$ Figure $^{\circ} 8^{\circ}$ the ion mobility spectra of sucrose (a nonreducing disaccharide) and maltose ( $\alpha$-D-Glcp-(1-4)-D-Glc, a reducing disaccharide) are shown. Sucrose yielded a single peak, whereas maltose yielded five IMS peaks. This indicates that the reducing sugar in maltose is probably present in different configurations, possibly even the openchain form, and potentially that different locations for metal ion adduction are possible. Of interest was that isomaltose ( $\alpha$-D-Glc $p$-(1-6)-D-Glc), which is also a reducing ${ }^{\circ}$ disaccharide, ${ }^{\circ}$ yielded $^{\circ}$ just $^{\circ}$ one $^{\circ}$ peak $^{\circ}\left(\right.$ Table $\left.^{\circ} 4\right)$. These experiments, along with those previously reported $^{\circ}[31]^{\circ}$ indicate $^{\circ}$ that $^{\circ} \mathrm{a}^{\circ}$ reducing $^{\circ}$ sugar $^{\circ}$ usually complicates analyses of disaccharides, that if a reducing structure yields just one peak it is either due to one dominant adduct or coincidental co-migration of more 
Table 4. Drift times and reduced mobilities determined for some sodiated adducts of reducing monosaccharides and some disaccharides employing ion mobility/mass spectrometry ${ }^{a}$

\begin{tabular}{lcc}
\hline Compound & $m / z$ & Drift times and reduced mobilities (bracketed) for ion mobility peaks \\
\hline \hline Glucose $^{\mathrm{c}}$ & 203 & $11.80(1.52) ; 12.14(1.48) ; 12.31(1.46)$ \\
Fructose $^{\mathrm{c}}$ & 203 & $12.13(1.48) ; 12.23(1.47)$ \\
Ribose $^{\mathrm{c}}$ & 173 & $11.41(1.58)$ \\
Xylose $^{\mathrm{c}}$ & 173 & $11.13(1.62) ; 11.36(1.58)$ \\
Sucrose $^{\mathrm{d}}$ & 365 & $19.02(1.27)$ \\
Maltose $^{\mathrm{d}}$ & 365 & $19.56(1.23) ; 19.24(1.25) ; 20.48(1.18) ; 21.09(1.14)$, and $21.58(1.12)$ \\
Isomaltose $^{\mathrm{d}}$ & 365 & $19.65(1.23)$ \\
\hline
\end{tabular}

${ }^{a} \mathrm{~N}_{2}$ was used as the drift gas at $\sim 1300 \mathrm{~mL} / \mathrm{min}$.

${ }^{b}$ Reduced mobility in $\mathrm{cm}^{2} \mathrm{~V}^{-1} \mathrm{~s}^{-1}$.

'Denotes measurements performed at $514 \mathrm{~V} / \mathrm{cm}$ and $699 \mathrm{~mm} \mathrm{Hg}$ pressure.

${ }^{\mathrm{d} D e n o t e s}$ measurements performed at $412 \mathrm{~V} / \mathrm{cm}$ and $700 \mathrm{~mm} \mathrm{Hg}$ pressure.

than one, and that it is in most cases desirable to reduce a larger oligosaccharide with sodium borohydride to the alditol at the reducing end to simplify analyses.

\section{Conclusions}

Separation of metal adducts of anomeric methyl glycoside isomers (MeMan, MeGal, and MeGlc) and isomeric forms of reducing sugars were achieved using ESIAPIMS-TOFMS. Methyl glycosides yielded single IMS peaks, but more than one peak was typically observed for free reducing monosaccharides suggesting that in the gas phase different anomers and ring forms of reducing monosaccharides might be differentiated by APIMS. Ion mobility profiles of reducing monosaccharides examined at given $\mathrm{m} / \mathrm{z}$ values were unique and may enable them to be identified in the future as product ions derived from larger oligosaccharides when used in combination with gas-phase isolation/ dissociation techniques.

Both the nature of the metal cation complex used for adduction and the drift gas employed in the IMS influenced separation between carbohydrate isomers in independent and often unpredictable ways. However, regardless of the nature of the drift gas or metal ion complex, the $\alpha$-methylglycosides invariably had longer drift times (i.e., larger collisional cross-sections) than the $\beta$-anomers. Between sodium and cobalt acetate adducts, all 15 combinatorial pairs of these methyl hexopyranosides could be separated, which demonstrates the potential of ESI-APIMS-TOFMS as applied to structural elucidation of carbohydrates. Furthermore,

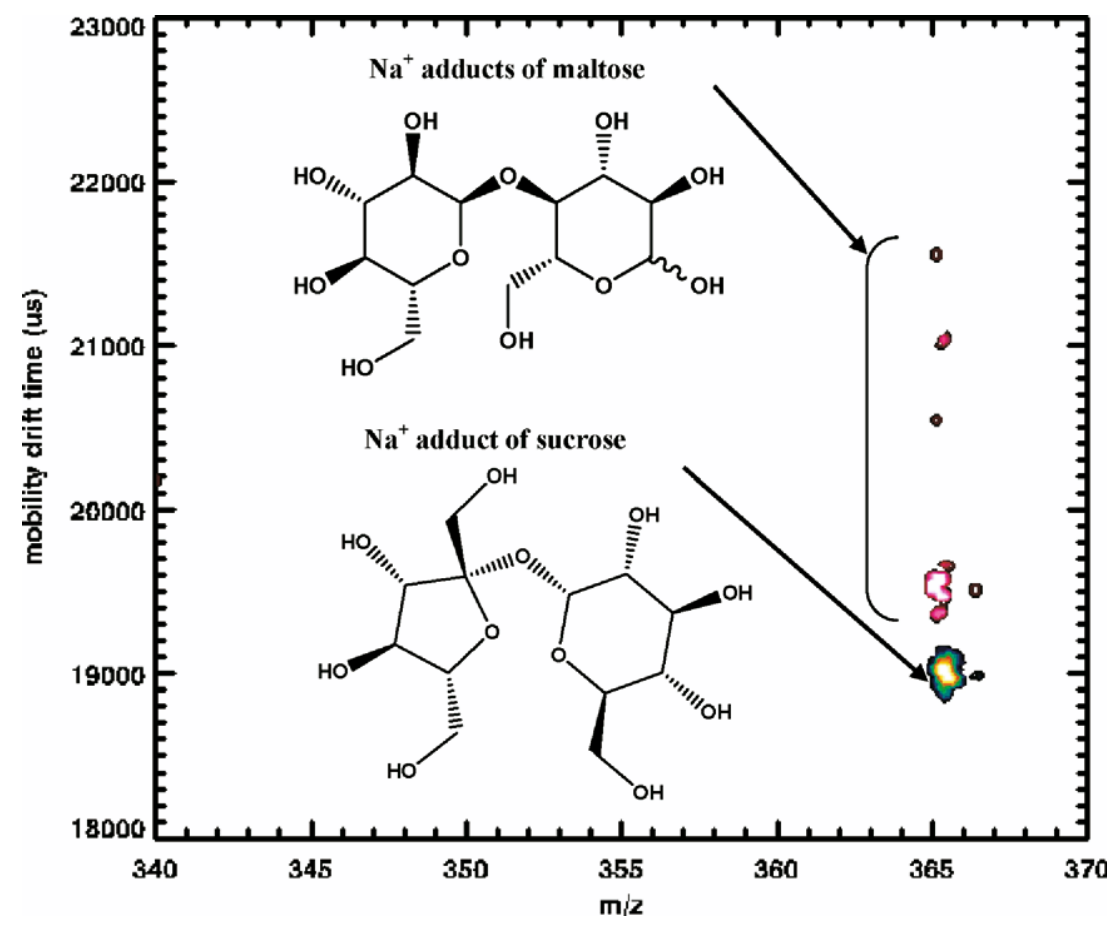

Figure 8. IMS separation of the disaccharides sucrose (nonreducing) and maltose (reducing) as sodium adducts $(\mathrm{m} / \mathrm{z}$ 365). Unlike sucrose multiple IMS peaks were observed for maltose, the drift times ${ }^{\circ}$ f $^{\circ}{ }^{\text {which }}{ }^{\circ}$ are ${ }^{\circ}$ listed $^{\circ}{ }^{\circ}{ }^{\circ}$ Table $^{\circ} 4$. 
other metal ions and metal ion complexes also markedly affected the resolution of isomers and when used orthogonally to different drift gases, a number of physically alterable properties can be easily varied to attempt to elicit separations of sugar isomers. While these studies have been largely carried out with simple glycosides and reducing sugars, the fundamental advantage of ambient pressure IMS to separate ions based on their size when conjugated with MS provides a high-resolution analytical tool that can be applied to separation of isomeric ions either before or after dissociation events. This may have great value in rapidly evaluating suspected isomeric mixtures of oligosaccharides through arrays of multiple experimental conditions. It also seems reasonable to surmise that many other metal-centered ion complexes, different counterions of salts, and drift gases of different selectivity along with optimization of instrumental parameters, might be exploited to further enhance the flexibility of IMS as applied to carbohydrate structure analyses.

\section{Acknowledgments}

The authors acknowledge Agnes Tempez, Thomas F. Egan, and Albert J. Schultz from Ionwerks Inc. (Houston, TX) for their contribution in the construction of high-resolution APIMSTOFMS. This work was supported in part by a grant from the National Institute of Health-National Center for Research Resources (R21 DK 070274). BB also acknowledges NSF grant CHE0137986 for partial support.

\section{References}

1. Taylor, M. E.; Drickamer, K. Introduction to Glycobiology; Oxford University Press: Oxford, UK, 2003 p. 1.

2. Muntoni, F.; Brockington, M.; Blake, D. J.; Torelli, S.; Brown, S. C. Defective Glycosylation in Muscular Dystrophy. Lancet 2002, 360(9343), 1419-1421.

3. Hennet, T.; Ellies, L. G. The Remodeling of Glycoconjugates in Mice. Biochim. Biophy. Acta 1999, 1473(1), 123-136.

4. Gorelik, E.; Galili, U.; Raz, A. On the Role of Cell Surface Carbohydrates and their Binding Proteins (lectins) in Tumor Metastasis. Cancer Metast. Rev. 2002, 20(3/4), 245-277.

5. Gabius, H. J.; Andre, S.; Kaltner, H.; Siebert, H. C. The Sugar Code: Functional Lectinomics. Biochim. Biophys. Acta. 2002, 1572(2/3), 165-177.

6. Zaia, J. Mass Spectrometry of Oligosaccharides. Mass Spectrom. Rev. 2004, 23(3), 161-227.

7. Park, Y.; Lebrilla, C. B. Application of Fourier Transform Ion Cyclotron Resonance Mass Spectrometry to Oligosaccharides. Mass Spectrom. Rev. 2005, 24(2), 232-264.

8. Morelle, W.; Michalski, J. C. The Mass Spectrometric Analysis of Glycoproteins and Their Glycan Structures. Curr. Anal. Chem. 2005, 1(1), $29-57$

9. Lindberg, B.; Lonngren, J. Methylation Analysis of Complex Carbohydrates: General Procedure and Application for Sequence Analysis. Methods Enzymol. 1978, 50, 3-33.

10. Seymour, F. R. Identification and Characterization of Saccharides by GLC (Gas-Liquid Chromatography) Separation and MS Analysis of their Peracetylated Aldononitrile (PAAN) and Keto-oxime (PAKO) Derivatives. Methods Carbohydr. Chem. 1993, 9, 59-85.

11. Bendiak, B.; Fang, T. T. End-Group Determination of Oligosaccharides: A Gas Chromatography-Mass Spectrometry/Mass Spectrometry Method for Distinguishing Between All D-Aldohexoses and DKetohexoses. Carbohydr. Res. 2000, 327(4), 463-481.

12. Revercomb, H. E.; Mason, E. A. Theory of Plasma Chromatography/ Gaseous Electrophoresis-A Review. Anal. Chem. 1975, 47(7), 970.

13. Eiceman, G. A.; Karpas, Z. Ion Mobility Spectrometry, 2nd ed.; 2004, Boca Raton, FL: CRC Press, p 350.
14. Bendiak, B.; Martensson, S.; Levery, S. B.; Fang, T. T. Neutral Core Oligosaccharides of Bovine Submaxillary Mucin-Use of Lead TetraAcetate in the Cold for Establishing Branch Positions. Eur. J. Biochem. 1998, 258(2), 603-622.

15. Cumming, D. A.; Hellerqvist, C. G.; Harris-Brandts, M.; Michnick, S. W. Carver, J. P.; Bendiak, B. Structures of Asparagine-Linked Oligosaccharides of the Glycoprotein Fetuin Having Sialic Acid Linked to NAcetylglucosamine. Biochemistry 1989, 28(15), 6500-6512.

16. Kamerling, J. P.; Vliegenthart, J. F. G. High-Resolution Proton-Nuclear Magnetic Resonance Spectroscopy of Oligosaccharide-Alditols Released from Mucin-Type O-Glycoproteins. Biol. Magnetic Res. 1992, 10, 1-144.

17. Karlsson, N. G.; Schulz, B. L.; Packer, N. H. Structural Determination of Neutral O-Linked Oligosaccharide Alditols by Negative Ion LC-ElectrosprayMS(n). J. Am. Soc. Mass Spectrom. 2004, 15(5), 659-672.

18. Ashline, D.; Singh, S.; Hanneman, A.; Reinhold, V. Congruent Strategies for Carbohydrate Sequencing. 1. Mining Structural Details by MS(n). Anal. Chem. 2005, 77(19), 6250-6262.

19. Zhang, H.; Singh, S.; Reinhold, V. N. Congruent strategies for carbohydrate sequencing. 2. FragLib: An MS ( $n)$ spectral library. Anal. Chem. 2005, 77(19), 6263-6270.

20. Desaire, H.; Leary, J. A. Multicomponent Quantification of Diastereomeric Hexosamine Monosaccharides Using Ion Trap Tandem Mass Spectrometry. Anal. Chem. 1999, 71(19), 4142-4147.

21. Gaucher, S. P.; Morrow, J.; Leary, J. A. STAT: A Saccharide Topology Analysis Tool Used in Combination with Tandem Mass Spectrometry. Anal. Chem. 2000, 72(11), 2331-2336.

22. Wu, C.; Siems, W. F.; Asbury, G. R.; Hill, H. H. Electrospray Ionization High-Resolution Ion Mobility Spectrometry-Mass Spectrometry. Anal. Chem. 1998, 70(23), 4929-4938.

23. Steiner, W. E.; Clowers, B. H.; Fuhrer, K.; Gonin, M.; Matz, L. M.; Siems, W. F.; Schultz, A. J.; Hill, H. H. Electrospray Ionization with Ambient Pressure Ion Mobility Separation and Mass Analysis by Orthogonal Time-of-Flight Mass Spectrometry. Rapid Commun. Mass Spectrom. 2001, 15(23), 2221-2226.

24. Collins, D. C.; Lee, M. L. Developments in Ion Mobility SpectrometryMass Spectrometry. Anal. Bioanal. Chem. 2002, 372(1), 66-73.

25. Cohen, M. J.; Carroll, D. I.; Wernlund, R. F.; Kilpatrick, W. D. Apparatus and Methods for separating, concentrating, and measuring gas traces. Ger Offen Patent no. 3,699,333, 1971; Germany.

26. Gabryelski, W.; Froese, K. L. Rapid and Sensitive Differentiation of Anomers, Linkage, and Position Isomers of Disaccharides Using HighField Asymmetric Waveform Ion Mobility Spectrometry (FAIMS). J. Am. Soc. Mass Spectrom. 2003, 14(3), 265-277.

27. Leavell, M. D.; Gaucher, S. P.; Leary, J. A.; Taraszka, J. A.; Clemmer, D. E. Conformational Studies of Zn-Ligand-Hexose Diastereomers Using Ion Mobility Measurements and Density Functional Theory Calculations. J. Am. Soc. Mass Spectrom. 2002, 13(3), 284-293.

28. Lee, D. S.; Wu, C.; Hill, H. H. Detection of Carbohydrates by Electrospray Ionization Ion Mobility Spectrometry Following Microbore HighPerformance Liquid Chromatography. J. Chromatogr. A 1998, 822(1), 1-9.

29. Lee, S.; Wyttenbach, T.; Bowers, M. T. Gas-Phase Structures of Sodiated Oligosaccharides by Ion Mobility Ion Chromatography Methods. Int. J. Mass Spectrom. 1997, 167, 605-614.

30. Liu, Y. S.; Valentine, S. J.; Counterman, A. E.; Hoaglund, C. S.; Clemmer, D. E. Injected-Ion Mobility Analysis of Biomolecules. Anal. Chem. 1997, 69(23), A728-A735.

31. Clowers, B. H.; Dwivedi, P.; Steiner, W. E.; Hill, H. H.; Bendiak, B. Separation of Sodiated Isobaric Disaccharides and Trisaccharides Using Electrospray Ionization-Atmospheric Pressure Ion Mobility-Time of Flight Mass Spectrometry. J. Am. Soc. Mass Spectrom. 2005, 16(5), $660-669$.

32. Steiner, W. E.; Clowers, B. H.; Fuhrer, K.; Gonin, M.; Matz, L. M.; Siems, W. F.; Schultz, A. J.; Hill, H. H., Jr. Electrospray Ionization with Ambient Pressure Ion Mobility Separation and Mass Analysis by Orthogonal Time-of-Flight Mass Spectrometry. Rapid Commun. Mass Spectrom. 2001 15(23), 2221-2226.

33. Asbury, G. R.; Hill, H. H. Evaluation of Ultrahigh Resolution Ion Mobility Spectrometry as an Analytical Separation Device in Chromatographic Terms. J. Microcolumn Sep. 2000, 12(3), 172-178.

34. Wu, C.; Siems, W. F.; Asbury, G. R.; Hill, H. H., Jr. Electrospray Ionization High-Resolution Ion Mobility Spectrometry-Mass Spectrometry. Anal. Chem. 1998, 70(23), 10.

35. Asbury, G. R.; Hill, H. H. Using Different Drift Cases to Change Separation Factors $(\alpha)$ in Ion Mobility Spectrometry. Anal. Chem. 2000, 72(3), 580-584

36. Beegle, L. W.; Kanik, I.; Matz, L.; Hill, H. H. Effects of Drift-Gas Polarizability on Glycine Peptides in Ion Mobility Spectrometry. Int. J. Mass Spectrom. 2002, 216(3), 257-268.

37. Matz, L. M.; Hill, H. H., Jr.; Beegle, L. W.; Kanik, I. Investigation of Drift Gas Selectivity in High Resolution Ion Mobility Spectrometry with Mass Spectrometry Detection. J. Am. Soc. Mass Spectrom. 2002, 13(4), 300-307.

38. Rokushika, S.; Hatano, H.; Hill, H. H. Ion Mobility Spectrometry in Carbon Dioxide. Anal. Chem. 1986, 58(2), 361-365. 